\title{
Thorium Dioxide
}

National Cancer Institute

\section{Source}

National Cancer Institute. Thorium Dioxide. NCI Thesaurus. Code C1449.

A radioactive crystalline solid compound used in a broad range of industrial applications.

Thorium dioxide was utilized as a radiographic contrast agent; however, it is no longer considered safe for use in human patients because it was found to be a carcinogen that can cause cholangiocarcinoma. 